\title{
FORMAÇÃO DE PROFISSIONAIS DA EDUCAÇÃO
}

\author{
FÓRUNS ESTADUAIS PERMANENTES DE \\ APOIO À FORMAÇÃO DOCENTE: \\ CRÔNICA DE UMA MORTE ANUNCIADA*
}

\author{
Cleomar Locatelli ${ }^{1} \oplus$ \\ Júlio Emílio Diniz-Pereira² •
}

\begin{abstract}
RESUMO: Este artigo apresenta um panorama sobre a curta trajetória dos Fóruns Estaduais Permanentes de Apoio à Formação Docente no Brasil, criados para cumprir objetivos da Política Nacional de Formação de Profissionais do Magistério. O propósito deste texto é analisar a efetiva constituição e o funcionamento dos referidos fóruns, ao avaliar sua estruturação como política nacional, seu caráter permanente e a realização de suas finalidades. Além da base legal, a pesquisa verificou um conjunto de informaçóes referentes ao tema disponível na página eletrônica da Coordenação de Aperfeiçoamento de Pessoal de Nível Superior (CAPES). Constatou-se que, em um período de aproximadamente seis anos (2009-2015), com grande diversidade na adesão e na orientação, os fóruns surgiram e desapareceram, revelando a desarticulação e a impotência deles para lidar com os graves problemas da formação docente no Brasil.

Palavras-chave: Formação de professores. Políticas docentes. Regime de colaboração.
\end{abstract}

\section{PERMANENT STATE FORUMS IN SUPPORT OF TEACHER EDUCATION: CHRONICLE OF A DEATH FORETOLD}

ABSTRACT: This paper analyzes the Permanent State Forums of Support to Teacher Education, created to fulfill the objectives of the National Policy for Schoolteachers Training in Brazil. The goal is to identify the effective constitution and functioning of these forums, analyzing their structure as a national policy, its permanent character and the accomplishment of its

\footnotetext{
*Este artigo apresenta resultados do projeto de pesquisa de pós-doutorado: "A política nacional de formação de professores: açôes, tendências e perspectivas", desenvolvido no Programa de Pós-Graduação da Faculdade de Educação (FaE/UFMG).

${ }^{1}$ Universidade Federal do Tocantins, Curso de Pedagogia - Tocantinópolis (TO), Brasil.

E-mail: locatelli@uft.edu.br

${ }^{2}$ Universidade Federal de Minas Gerais, Programa de Pós-graduação da Faculdade de Educação -

Belo Horizonte (MG), Brasil. E-mail: juliodiniz@ufmg.br

DOI: 10.1590/ES0101-73302019186542
} 
purposes. The research gathered the legal basis and other information available on the CAPES website. It was found that in a period of approximately six years (2009-2015), with great diversity in adherence and orientation, forums emerged and disappeared, revealing their disarticulation and impotence in dealing with the serious problems of teacher education in Brazil.

Keywords: Teacher education. Teacher education policy. Regime of collaboration.

\section{Fórums Estaduales Permanentes de APOYO A LA FORMACión DOCENTE: CRÓNICA DE UNA MUERTE ANUNCIADA}

RESUMEN: Este artículo presenta un panorama sobre la corta trayectoria de los Fórums Estaduales Permanentes de Apoyo a la Formación Docente en Brasil, creados para cumplir objetivos de la Política Nacional de Formación de Profesionales del Magisterio. El propósito de este texto es analizar la efectiva constitución y el funcionamiento de los referidos fórums, al evaluar su estructuración como política nacional, su carácter permanente y la realización de sus finalidades. Además de la base legal, el estudio verifico un conjunto de informaciones referentes al tema disponible en la página electrónica de la Coordinación de Perfeccionamiento de Personal de Nivel Superior (CAPES). Se constató que, en un período de aproximadamente seis años (2009-2015), con gran diversidad em la adhesión y en la orientación, los fórums surgieron y desaparecieron, revelando la desarticulación y su impotencia para lidiar con los graves problemas de la formación docente en Brasil.

Palabras-clave: Formación de profesores. Políticas docentes. Régimen de colaboración.

\section{Introdução}

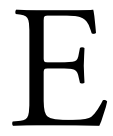

ste artigo discute a política nacional de formação docente para a educação básica nos últimos anos e, para tal, analisa, particularmente, a criação e o desenvolvimento dos Fóruns Estaduais Permanentes de Apoio à Formação Docente no Brasil. Essa iniciativa, estabelecida pelo Decreto no 6.755 , de 29 de janeiro de 2009 (BRASIL, 2009a), definiu um novo arranjo para o regime de colaboração ${ }^{1}$ e instituiu uma nova fase da chamada "formação especial em serviço" no país. As principais finalidades dessa nova estrutura, constituída em cada Estado da federação brasileira, seriam: a identificação de necessidades formativas junto às redes e aos sistemas públicos de ensino, bem como a articulação de açóes visando suprir tais necessidades. 
Este artigo baseia-se em uma pesquisa documental que analisou atas de reuniōes dos fóruns publicadas na página eletrônica da Coordenação de Aperfeiçoamento de Pessoal de Nível Superior (CAPES), no período de julho de 2009 a março de 2016. Esses documentos de registro das reunióes foram a principal fonte de informaçóes da pesquisa. O referencial teórico utilizado ampara-se em autores que analisam as políticas docentes no Brasil.

Constatou-se que, em um curto espaço de tempo, a diluiçấo dos fóruns tornou-se um fato irreversível em razão, entre outras questóes, das dificuldades de articulação dos sujeitos envolvidos e do esgotamento das atividades do Plano Nacional de Formação de Professores da Educação Básica (Parfor). Embora seja necessário reconhecer que, em alguns casos, os fóruns representaram espaços de diálogo, de socialização de informaçôes e de deliberaçôes, em geral, eles revelaramse impotentes para tratar os problemas da formação docente no país. Os cursos aligeirados, as certificaçóes em massa e outros aspectos referentes à qualidade das licenciaturas, que se mostram recorrentes nas pesquisas sobre formação inicial de professores para a educação básica (GATTI, 2014), embora presentes em muitas discussóes, não foram devidamente enfrentados por esses colegiados.

\section{A origem, a tarefa e a composição dos fóruns}

O Decreto no 6.755, de 29 de janeiro de 2009, que institui a Política Nacional de Formação de Professores da Educação Básica, reproduz uma tradição brasileira em termos de formação docente: ele volta-se, mais uma vez, para açôes emergenciais e provisórias direcionadas para aqueles que se encontram em pleno exercício da docência. A formaçáo inicial que acontece nas instituiçóes de ensino superior (IESs), por meio dos diversos cursos de licenciatura, permanece praticamente inalterada no cenário nacional. $\mathrm{O}$ art. $3^{\circ}$, inciso IV, do referido documento, ao especificar como um de seus objetivos: "identificar e suprir a necessidade das redes e sistemas públicos de ensino por formação inicial e continuada de profissionais do magistério" (BRASIL, 2009a), define - como público-alvo de suas açóes — os professores da educação básica em serviço nas redes públicas de ensino.

Açóes emergenciais - para "formar" os professores que se encontram em efetivo exercício e que não contam com os requisitos mínimos exigidos para a funçấo docente - não são uma novidade na realidade brasileira. A necessidade de tais açóes (emergenciais) atrela-se à incômoda existência do chamado professor leigo ${ }^{2}$ - uma figura que, infelizmente, nunca deixou de existir na história da educação brasileira. Na verdade, como observa Tanuri (2000), a participação estatal, na tarefa de preparar os professores para o exercício de suas funçôes, tem início, exatamente, com o objetivo de resolver o problema dos "professores leigos". 
Essa política, justificada então pela existência de um grande contingente de professores que atuam nas escolas básicas sem formação mínima exigida ${ }^{3}$, revela-se também alinhada às tendências internacionais das políticas docentes. Tais tendências apresentam uma concepção de preparação para a docência que tem a prática, situada no ambiente escolar, como lugar privilegiado de formação. Trata-se de um movimento reacionário e conservador que busca deslocar a formaçấo docente de uma perspectiva acadêmico-científica para o âmbito das práticas educativas (ZEICHNER, 2013).

É importante destacar que essa tem sido uma tendência das políticas docentes em toda a América Latina, em grande parte orientada por organismos internacionais. Segundo Torres (2000), a ênfase sobre a formação em serviço em detrimento da formação inicial faz parte de um conjunto de questóes que marcam as tendências atuais da formação docente na América Latina. Durante muito tempo, segundo a autora, criticou-se que os professores eram formados em escolas normais e universidades e, depois, deixados à própria sorte. Isso resultava em uma queixa constante sobre a necessidade de formaçóes permanentes. No entanto, a questão agora está invertida, os programas apresentados no âmbito das reformas atuais são, majoritariamente, de formação "em serviço". Nas palavras da autora, "ha habido un gran abandono de la formación inicial y una postergación de la indispensable reforma de las instituciones tradicionalmente formadoras de docente" (TORRES, 2000, p. 376).

$\mathrm{Na}$ legislação educacional brasileira da última década, observa-se que a oferta de cursos emergenciais de licenciatura se faz presente no Decreto Presidencial no 6.755/2009, no Plano Nacional de Educação (PNE), de 2014, e nas Diretrizes Curriculares Nacionais para a formação inicial em nível superior (cursos de licenciatura, cursos de formação pedagógica para graduados e cursos de segunda licenciatura) e para a formação continuada (Resolução CNE/CP no 2, de $1^{\circ}$ de julho de 2015). No referido decreto, art. 11, inciso III, atribui-se à CAPES a tarefa de fomentar

[a] oferta emergencial de cursos de licenciaturas e de cursos ou programas especiais dirigidos aos docentes em exercício há pelo menos três anos na rede pública de educação básica, que sejam: a) graduados náo licenciados; b) licenciados em área diversa da atuação docente; e c) de nível médio, na modalidade Normal (BRASIL, 2009a).

No PNE (2014), mais especificamente na meta 15.9, também se observa uma manifestação referente ao caso dos professores em exercício. Essa meta propóe:

15.9) implementar cursos e programas especiais para assegurar formação específica na educação superior, nas respectivas áreas de atuaçãa, aos docentes com formação de nível médio na 
modalidade normal, não licenciados ou licenciados em área diversa da de atuaçáo docente, em efetivo exercício (BRASIL, 2014).

Em linhas gerais, o PNE/2014 reproduz o que foi determinado pelo Decreto 6.755, ao enfatizar que a implementação de cursos e programas especiais deverá ser "nas respectivas áreas de atuação" (BRASIL, 2014), reforçando, sobretudo, a necessária preparação no que se refere aos conteúdos a serem ensinados.

$\mathrm{Na}$ Resolução CNE/CP no 2/2015, nos arts. 14 e 15, os cursos emergenciais e provisórios referem-se à segunda licenciatura e à formação pedagógica para graduados não licenciados. Em ambos os casos, determina-se carga horária reduzida, variando conforme a situação a ser atendida, e, no caso do curso para segunda licenciatura, conforme se estabelece no $\$ 7^{\circ}$ do art. 15, "Os portadores de diploma de licenciatura com exercício comprovado no magistério e exercendo atividade docente regular na educação básica poderão ter redução da carga horária do estágio curricular supervisionado até o máximo de 100 (cem) horas" (BRASIL, 2015b).

Embora ninguém duvide da real necessidade da formação de professores em exercício, essas determinaçôes legais revelam que continuamos a reproduzir a tradição brasileira na preparação para o magistério, em que situaçóes incongruentes ou "não ideais" junto às redes de ensino justificam açóes emergenciais e provisórias, reduzindo-se a esse campo, quase que, exclusivamente, a presença estatal na preparação dos docentes da educação básica no país.

Percebe-se que a priorização da formação em serviço, que leva o ensino superior até os professores, sem, necessariamente, adotar todos os ritos e procedimentos do campo universitário, alinha-se a uma perspectiva que valoriza a "capacitação" prática e focalizada, voltada para ajudar o professor a resolver os problemas imediatos da sala de aula, bem como de aproveitamento dos conhecimentos práticos e da vida prática. Nessa última situação, segundo Maués (2003, p. 102-3), "em alguns casos, esse aproveitamento tem servido para enriquecer a formação e valorizar as experiências existentes, mas, em outros, tem contribuído para diminuir a duração dos cursos e aligeirar a formação, aumentando assim o número de diplomados".

No entanto, a instituição da Política Nacional de Formação de Profissionais do Magistério da Educação Básica no Brasil - embora signatária dessa mesma concepção, tendo em vista a histórica ausência de uma política nacional de formação docente - também gerou expectativas positivas, principalmente com a criação dos Fóruns Estaduais Permanentes de Apoio à Formação Docente. Nas palavras de Freitas (2012, p. 212),

A principal conquista do decreto foi a instituição de fóruns estaduais permanentes de apoio à formação docente em cada estado, com a responsabilidade de elaborar o Plano Estratégico 
da Formação e criar as condiçóes — administrativas, financeiras e pedagógicas - para o pleno desenvolvimento dos programas de formação.

De fato, para o alcance dos objetivos estabelecidos no Decreto no 6.755/2009, deveria ser elaborado, em cada Estado e no Distrito Federal, pelos referidos fóruns, um plano estratégico que contemplasse: diagnóstico e identificação de necessidades de formação, definição das ações a serem desenvolvidas e atribuição de responsabilidades. Essas questóes estáo definidas no art. $5^{\circ}$ do referido decreto, que ainda detalha, no $\$ 1^{\circ}$, os seguintes pontos a serem discriminados no diagnóstico:

I — os cursos de formação inicial; II — os cursos e atividades de formação continuada; III - a quantidade, o regime de trabalho, o campo ou a área de atuaçáo dos profissionais do magistério a serem atendidos; e IV — outros dados relevantes que complementem a demanda formulada (BRASIL, 2009a).

A composição dos fóruns em cada Estado (e no Distrito Federal) também foi prevista nesse decreto (art. $4^{\circ}$, incisos I a VIII). Os assentos garantidos foram distribuídos da seguinte forma: duas vagas para o governo do Estado ou do Distrito Federal, sendo uma do(a) Secretário(a) de Educação, que passa a ser, automaticamente, o presidente; uma vaga para o Ministério da Educação; dois representantes dos(as) Secretários(as) Municipais de Educação indicados pela respectiva seção regional da Uniāo Nacional dos Dirigentes Municipais de Educação (Undime); o dirigente máximo de cada instituição pública de educação superior com sede no Estado ou no Distrito Federal, ou seu representante; um representante dos profissionais do magistério, indicado pela seccional da Confederação Nacional dos Trabalhadores em Educação (CNTE); um representante do Conselho Estadual de Educação; um representante da União Nacional dos Conselhos Municipais de Educação (UNCME); e um representante do Fórum das Licenciaturas das Instituições de Educação Superior Públicas, quando houver.

O decreto estabeleceu, então, que a presidência do fórum fosse atribuída ao(à) secretário(a) de Educação, mas que, em sua ausência, o plenário do colegiado poderia indicar um substituto. Esse documento definiu também que outros órgãos, instituições ou entidades locais poderiam fazer parte do fórum, solicitando adesão, e que, conforme o $\$ 7^{\circ}$ do art. $4^{\circ}$, o fórum deveria elaborar suas normas internas de funcionamento, segundo diretrizes nacionais fixadas pelo Ministério da Educação.

A seguir, utilizando as informaçóes disponíveis na página eletrônica da CAPES, apresentaremos um panorama sobre a criação e o funcionamento dos fóruns em todos os Estados e no Distrito Federal, destacando o número de reuniōes, 
as datas em que foram realizadas e se há ou não a disponibilidade de outros documentos, como o regimento interno do colegiado e o planejamento estratégico. No tópico seguinte, realizaremos uma análise mais minuciosa, com um grupo menor de fóruns, destacando a elaboração, implementação e avaliação do planejamento estratégico, os principais assuntos tratados e as principais questóes e problemas abordados.

\section{A Constituição e o funcionamento dos fóruns em todos os estados brasileiros}

No Quadro 1, podemos observar que, com exceção do Mato Grosso do Sul, que não disponibilizou nenhuma informação no portal da Capes, para os demais Estados há algum registro sobre a existência e funcionamento de Fóruns Estaduais Permanentes de Apoio à Formação Docente. Percebe-se também que há grandes diferenças entre esses fóruns em relação ao número de reuniōes realizadas: enquanto em alguns Estados, como Paraíba e Bahia, foram realizadas 35 e 30 reuniôes respectivamente, em outros, como nos casos de Sergipe e do Maranhão, há o registro de apenas uma reunião em cada um deles.

A criação dos fóruns ou o início dos trabalhos em cada Estado, considerando-se a realização da primeira reunião, também guarda bastante variação de uma realidade para outra: enquanto a primeira reunião do fórum no Mato Grosso foi em julho de 2009, no Rio Grande do Sul, isso ocorreu quase dois anos depois, em março de 2011. Da mesma forma, quando observamos a data da última reuniáo, podemos notar que, também, variou bastante. Excluindo os Estados que realizaram apenas uma reuniáo e o Rio de Janeiro, que realizou apenas duas reunióes, podemos notar que os registros no Espírito Santo e em Mato Grosso dáo conta da realização da última reunião em setembro de 2010; já em outros Estados, como Roraima e Amapá, verifica-se o registro das últimas reunióes quase cinco anos depois, em outubro de 2015 e março de 2016, respectivamente.

Quanto ao plano estratégico, cuja elaboração, acompanhamento, execução e revisão periódica caberiam ao fórum, não encontramos nenhum documento específico publicado no portal da CAPES. Embora não tenha sido estabelecida a obrigatoriedade da publicação de tal plano - considerando a sua centralidade para o desenvolvimento da política e o grau de detalhamento em que é apresentado no Decreto no 6.755/2009 e na Portaria no 883, de 16 de setembro de 2009 - , presume-se que não apenas a sua elaboração, mas também a sua divulgação seriam uma evidência importante sobre a realizaçáo das açóes referentes à formação docente em cada Estado.

No que se refere ao regimento interno dos fóruns, o art. $3^{\circ}, \mathbb{3} 3^{\circ}$, da portaria supracitada, estabelece prazos para sua elaboração e encaminhamen- 


\section{Quadro 1}

Informaçôes gerais sobre a existência e funcionamento dos fóruns em todos os Estados e no Distrito Federal.

\begin{tabular}{|c|c|c|c|c|c|}
\hline Estado & $\begin{array}{l}\text { Número } \\
\text { de } \\
\text { reunióes }\end{array}$ & $\begin{array}{l}\text { Primeira } \\
\text { reuniáo }\end{array}$ & $\begin{array}{l}\text { Última } \\
\text { reuniáo }\end{array}$ & $\begin{array}{l}\text { Disponibiliza o } \\
\text { regimento? }\end{array}$ & $\begin{array}{c}\text { Disponibiliza o } \\
\text { planejamento } \\
\text { estratégico? }\end{array}$ \\
\hline 1. Acre & 11 & $08 / 04 / 2010$ & $12 / 11 / 2013$ & Sim & Não \\
\hline 2. Alagoas & 07 & $10 / 12 / 2010$ & $13 / 02 / 2014$ & Não & Não \\
\hline 3. Amapá & 24 & $21 / 03 / 2012$ & $11 / 03 / 2016$ & Sim & Não \\
\hline 4. Amazonas & 08 (12?) & $12 / 11 / 2009$ & $26 / 10 / 2012$ & Sim & Não \\
\hline 5. Bahia & 30 & $21 / 01 / 2010$ & $08 / 08 / 2014$ & Não & Não \\
\hline 6. Ceará & 22 & $07 / 08 / 2009$ & $31 / 10 / 2014$ & Sim & Não \\
\hline $\begin{array}{l}\text { 7. Distrito } \\
\text { Federal }\end{array}$ & 10 & $02 / 08 / 2010$ & $23 / 07 / 2012$ & Não & Não \\
\hline 8. Espírito Santo & 05 & 07/12/2009 & $01 / 09 / 2010$ & Sim & Não \\
\hline 9. Goiás & 10 & $04 / 02 / 2010$ & $16 / 03 / 2011$ & Sim & Não \\
\hline 10. Maranhão & 01 & $01 / 09 / 2010$ & $01 / 09 / 2010$ & Sim & Não \\
\hline 11. Mato Grosso & 08 & $04 / 07 / 2009$ & $08 / 09 / 2010$ & Sim & Não \\
\hline $\begin{array}{l}\text { 12. Mato Grosso } \\
\text { do Sul }\end{array}$ & -- & -- & -- & -- & -- \\
\hline 13. Minas Gerais & 23 & 07/09/2009 & $01 / 07 / 2015$ & Sim & Não \\
\hline 14. Pernambuco & 23 & $18 / 12 / 2009$ & $27 / 01 / 2014$ & Sim & Não \\
\hline 15. Paraíba & 35 & $17 / 07 / 2009$ & $03 / 10 / 2014$ & Não & Não \\
\hline 16. Paraná & 16 & $16 / 11 / 2009$ & $22 / 09 / 2014$ & Sim & Não \\
\hline 17. Pará & 14 (24?) & $04 / 11 / 2009$ & $16 / 12 / 2011$ & Sim & Não \\
\hline 18. Piauí & 04 & $22 / 12 / 2009$ & $05 / 03 / 2012$ & Não & Não \\
\hline 19. Rio de Janeiro & 02 & $08 / 04 / 2010$ & $14 / 05 / 2010$ & Sim & Não \\
\hline $\begin{array}{l}\text { 20. Rio Grande } \\
\text { do Norte }\end{array}$ & 15 & $14 / 10 / 2009$ & $19 / 03 / 2013$ & Sim & Não \\
\hline $\begin{array}{l}\text { 21. Rio Grande } \\
\text { do Sul }\end{array}$ & 06 & $16 / 03 / 2011$ & $14 / 07 / 2012$ & Não & Não \\
\hline 22. Rondônia & 14 (19?) & $07 / 05 / 2010$ & $17 / 10 / 2014$ & Sim & Não \\
\hline 23. Roraima & 15 & $07 / 01 / 2010$ & $13 / 10 / 2015$ & Não & Não \\
\hline 24. Santa Catarina & $22(26 ?)$ & $06 / 10 / 2009$ & $14 / 11 / 2014$ & Sim & Não \\
\hline 25. São Paulo & 27 & $14 / 08 / 2009$ & $16 / 10 / 2014$ & Sim & Não \\
\hline 26. Sergipe & 01 & $13 / 04 / 2010$ & $13 / 04 / 2010$ & Sim & Não \\
\hline 27. Tocantins & 11 & $10 / 03 / 2010$ & $30 / 03 / 2015$ & Sim & Não \\
\hline
\end{tabular}

Fonte: Brasil (2010). 
to ao Ministério da Educação (MEC). Determinou-se, portanto, que os fóruns deveriam "elaborar suas normas internas de funcionamento no prazo máximo de 90 (noventa) dias, a contar da sua instalaçáo, as quais deverão ser encaminhadas ao MEC, para registro e verificação de sua adequação" (BRASIL, 2009b). Observamos que 19 Estados concluíram esse documento e o publicaram no portal da CAPES junto às atas de reunióes. Não há informações sobre os demais Estados.

Esse levantamento, que nos permite uma aproximação do contexto de criação e de funcionamento dos fóruns, evidencia o descompasso do desenvolvimento dessa ação como uma política nacional. $\mathrm{O}$ fato de haver Estados em que não se criaram os fóruns ou que, na verdade, fizeram apenas uma ou duas reuniōes, que demoraram muito para criá-los ou que, ao fazê-los, não deram continuidade às atividades, demonstra não apenas uma simples falta de adesão, mas a existência de grandes obstáculos para uma articulação nacional em torno das políticas de formação docente.

Tais obstáculos, que se evidenciam na particularidade da forma que cada Estado assumiu o trabalho em torno dos fóruns, compreendem uma realidade marcada por diversos fatores que não se limitam às necessidades ou aos níveis de estruturação da política de formação docente em cada local. Eles sugerem, para além das questôes específicas da formação docente, a existência de orientaçôes e definições de prioridades que refletem a submissão das políticas educacionais aos interesses de grupos políticos regionais. São especificidades da arquitetura governamental brasileira que possibilitam, em muitos casos, que as açóes articuladas nacionalmente sofram sérias resistências em alguns Estados, pelo fato de essas açóes virem de governantes não alinhados politicamente com o poder central. Um exemplo disso foi o que aconteceu com a chamada "Lei do Piso" (Lei no 11.738, de 16 de julho de 2008), em que alguns Estados, a maioria governada por integrantes de partidos de oposiçáo ao governo federal, recorreram à justiça por considerarem a lei inconstitucional.

Nesse conjunto de informaçóes, em que levantamos o número de reuniôes e o início e o término das atividades, fica evidente que a referida política atingiu as unidades da federação de maneira bastante desigual. Revelam-se as individualidades dos entes federados em relação à formação docente, bem como as resistências no que se refere à articulação das açóes e os obstáculos para o chamado regime de colaboração. Revelam-se ainda, entre outras questôes, as dificuldades organizativas das instituiçôes locais envolvidas com a formação e/ou a inadequação da política, concebida nacionalmente, diante da compreensão e da realidade local.

\section{O plano estratégico e outras atividades dos fóruns}

Como destacamos, para uma análise mais detalhada de alguns aspectos que julgamos relevantes, discutiremos a realidade dos fóruns de cinco Estados: 
Minas Gerais, Goiás, Paraíba, Santa Catarina e Tocantins. A escolha desses Estados se pautou em três critérios: primeiro, a definição de um Estado de cada região do país; segundo, a escolha dos Estados de Goiás, Paraíba e Santa Catarina, por serem os fóruns com maior número de reuniōes nas suas regiōes; e, terceiro, Tocantins e Minas Gerais, por serem os Estados em que trabalham os autores deste artigo, que, consequentemente, têm maior familiaridade com os seus contextos específicos. Essa seleção de um número menor de Estados tornou-se necessária em razão do volume de material a ser analisado: mais de 360 atas de reunióes disponíveis no portal da CAPES!

Por meio da leitura das atas de reunião dos cinco fóruns escolhidos, algumas questóes sobre o funcionamento dos fóruns nos chamaram atenção, entre elas, o fato de a participação de representantes do Ministério da Educação ou da CAPES não ter sido constante ou regular. Em alguns casos, como no Estado do Tocantins, constata-se a presença de um representante da CAPES em uma única reunião. Embora não tenhamos encontrado uma explicação formal para essa ausência, sabe-se que essas instituiçóes (MEC e CAPES) não contam mais com representaçóes permanentes em cada Estado - como existiam as Delegacias Regionais do MEC, extintas pelo governo Fernando Henrique Cardoso, nos anos 1990. Além disso, pode-se questionar sobre a adequação das estruturas (de recursos humanos e de recursos financeiros), sobretudo, no caso da Capes, ante as suas novas responsabilidades no que se refere à formação docente para educação básica, que lhe foram atribuídas pela Lei no 11.502 de 11 de julho de 2007.

Também nota-se que, na maioria dos casos analisados, a presidência do fórum não foi assumida pelo(a) secretário(a) de Estado da Educação ou por alguém escolhido no colegiado, visto ser essa uma determinação contida no próprio Decreto presidencial que lhe deu origem. Tal fato nos induz a questionar sobre a relevância assumida por esses órgãos colegiados na agenda dos gestores locais da educação. A exceção foi o estado da Paraíba onde verificamos que os(as) secretários(as) de Estado da Educação, que exerceram essa função ao longo do período analisado, presidiram boa parte das reuniôes e, na ausência deles(as), alguns dos seus representantes assumiram essa função. Em Minas Gerais, a presidência do fórum foi assumida, por um longo período, pelo Reitor da Universidade Federal de São João del-Rei (UFSJ) e, mais tarde, pela Secretária de Educação. Nos estados do Tocantins, Goiás e Santa Catarina, os respectivos fóruns foram presididos, em quase todas as reuniôes, por alguém da secretaria de educação, representando ou não o(a) Secretário(a) de Estado da Educação em exercício.

No Quadro 2, tem-se uma visão geral sobre os desdobramentos e o alcance dos fóruns, tendo em vista os registros referentes às suas reunióes. Para verificar o alinhamento dos fóruns com as atribuições que lhes foram conferidas, bem como para checar a centralidade de suas açóes e os principais problemas debatidos, reunimos informações sobre a construção do planejamento estratégico, 
os principais assuntos tratados nas reunióes e as questóes que geraram debates relevantes entre os integrantes de cada colegiado.

No que se refere ao planejamento estratégico, tarefa principal determinada pela legislação, cabendo ao fórum a sua elaboração, acompanhamento e avaliação, verificamos que em cada Estado se configurou uma realidade diferente e que, em nenhum dos casos verificados, diante das evidências contidas nas atas, o processo se desenvolveu dentro do que era esperado ou desejável. Percebe-se que, mesmo com todo o detalhamento apresentado no art. $5^{\circ}$ do Decreto $\mathrm{n}^{\circ}$ 6.755/2009, parte dos colegiados não atentou para a centralidade e a importância dessa tarefa. Outra parte parece não ter tido a compreensão necessária sobre o que se tratava, e outra, ainda, embora dimensionando nitidamente sua importância e finalidade, não desenvolveu - a contento - a tarefa do planejamento estratégico no tempo e na forma requeridos.

Ainda em relação ao plano estratégico, considerando os cinco fóruns analisados, constatamos três situaçóes ou formas de tratamento: a primeira, em que não se desenvolveu discussão alguma sobre elaboração, acompanhamento ou avaliação do plano; a segunda, em que o plano é apresentado pela Secretaria de Educação, instituindo-se, posteriormente, uma comissão para sua redefinição ou avaliação; e a terceira, em que se desenvolve uma importante discussão sobre a elaboração do planejamento estratégico, retornando diversas vezes à discussão, porém, sem chegar, necessariamente, a uma sistematização final.

\section{Quadro 2}

Plano estratégico, principais assuntos e questões-problema nas atas de reuniōes dos fóruns.

\begin{tabular}{|c|c|c|c|}
\hline Estado & $\begin{array}{l}\text { Referências à } \\
\text { elaboraçáo do } \\
\text { plano estratégico }\end{array}$ & $\begin{array}{l}\text { Principais assuntos } \\
\text { tratados }\end{array}$ & Questóes-problema em debate \\
\hline Tocantins & $\begin{array}{l}\text { Náo há referências } \\
\text { sobre elaboração, } \\
\text { acompanhamento } \\
\text { ou avaliação do } \\
\text { plano estratégico. } \\
\text { Há referência ao } \\
\text { Parfor/UFT. }\end{array}$ & $\begin{array}{l}\text { Vagas para o Parfor } \\
\text { presencial e a distância. } \\
\text { Calendário de realização dos } \\
\text { cursos Parfor. } \\
\text { Sorteio de candidatos } \\
\text { inscritos em alguns cursos } \\
\text { do Parfor. } \\
\text { Apresentação de demandas } \\
\text { de formação pelas secretarias } \\
\text { do Estado e dos municípios. }\end{array}$ & $\begin{array}{l}\text { Quais as instituições que podem } \\
\text { ou devem ofertar cursos pelo } \\
\text { sistema UAB. } \\
\text { Atendimento aos cursistas Parfor, } \\
\text { principalmente aqueles da zona } \\
\text { rural. } \\
\text { Desinteresse dos professores pelas } \\
\text { vagas oferecidas (principalmente } \\
\text { segunda licenciatura). } \\
\text { Dificuldade em relação às } \\
\text { informaçóes corretas sobre } \\
\text { demandas de formação. }\end{array}$ \\
\hline
\end{tabular}

Continua... 


\section{Quadro 2}

Continuação

\begin{tabular}{|c|c|c|c|}
\hline $\begin{array}{l}\text { Minas } \\
\text { Gerais }\end{array}$ & $\begin{array}{l}\text { Há referências } \\
\text { sobre discussão, } \\
\text { finalização e } \\
\text { aprovação do } \\
\text { planejamento } \\
\text { estratégico } \\
\text { nas primeiras } \\
\text { reuniôes. } \\
\text { Verifica-se a } \\
\text { criação de uma } \\
\text { comissão para } \\
\text { reavaliar o plano. }\end{array}$ & $\begin{array}{l}\text { Criação e avaliação de polos } \\
\text { da UAB que oferecem vagas } \\
\text { para licenciatura. } \\
\text { Ofertas de vagas para } \\
\text { o Parfor presencial e a } \\
\text { distância. } \\
\text { Criação de polos da Uaitec } \\
\text { Validação das inscriçóes na } \\
\text { Plataforma Paulo Freire. } \\
\text { Mestrado profissional } \\
\text { e proposta de curso de } \\
\text { especialização. }\end{array}$ & $\begin{array}{l}\text { Divergências de avaliação do } \\
\text { MEC e das universidades em } \\
\text { reação aos polos a UAB. } \\
\text { Ausência da formação continuada } \\
\text { no plano estratégico. } \\
\text { Informações equivocadas na } \\
\text { plataforma e dificuldade de } \\
\text { atender o público que realmente } \\
\text { precisa. }\end{array}$ \\
\hline Goiás & $\begin{array}{l}\text { Várias referências } \\
\text { sobre o processo } \\
\text { de elaboração do } \\
\text { planejamento } \\
\text { estratégico. } \\
\text { Porém, não se } \\
\text { observa ter havido } \\
\text { uma conclusão. }\end{array}$ & $\begin{array}{l}\text { Apresentação das } \\
\text { necessidades de formação de } \\
\text { professores em serviço no } \\
\text { Estado. } \\
\text { Criação de polos de apoio } \\
\text { presencial da UAB em } \\
\text { municípios do interior. } \\
\text { Demanda da Plataforma } \\
\text { Freire e oferta de cursos e } \\
\text { vagas Parfor nas IESs no } \\
\text { Estado. } \\
\text { Regulamentação das pós } \\
\text { latu senso }\end{array}$ & $\begin{array}{l}\text { Orientação do CNE para cursos } \\
\text { presenciais e as possibilidades de } \\
\text { oferecer a distância. } \\
\text { Falta de condiçóes para } \\
\text { funcionamento dos polos, e } \\
\text { resistência da UFG em ofertar } \\
\text { cursos a distância. } \\
\text { Portadores de diplomas que não } \\
\text { são portadores de conhecimento. } \\
\text { Dificuldades para realização de } \\
\text { segunda licenciatura por porte } \\
\text { dos professores. } \\
\text { Dificuldades com a plataforma } \\
\text { Freire, poucas matrículas nos } \\
\text { cursos abertos pelas IESs. } \\
\text { Muitas vagas abertas não } \\
\text { preenchidas. }\end{array}$ \\
\hline Paraíba & $\begin{array}{l}\text { O planejamento } \\
\text { estratégico foi } \\
\text { citado como } \\
\text { ponto de pauta } \\
\text { retornando em } \\
\text { várias reuniōes. }\end{array}$ & $\begin{array}{l}\text { Currículo diferenciado para } \\
\text { os cursos oferecidos no } \\
\text { modelo Parfor. } \\
\text { Alocação dos polos de apoio } \\
\text { presencial da UAB. } \\
\text { Critérios de validações de } \\
\text { inscriçóes dos professores } \\
\text { (efetivos ou não). } \\
\text { Oferta de vagas para o } \\
\text { Parfor pelas IESs, validação } \\
\text { das inscrições. } \\
\text { Manuseio da Plataforma Freire. }\end{array}$ & $\begin{array}{l}\text { Problemas com a plataforma } \\
\text { Freire: acesso, inscrição etc. } \\
\text { A construção de uma proposta } \\
\text { diferenciada, náo só para o } \\
\text { público do Parfor, como também } \\
\text { para UAB. } \\
\text { Sobre o processo seletivo que não } \\
\text { é padronizado e que acaba ficando } \\
\text { sem sentido. A seleçáo dos } \\
\text { melhores ou dos que precisam? }\end{array}$ \\
\hline
\end{tabular}

Continua... 


\section{Quadro 2}

Continuação

\begin{tabular}{|c|c|c|c|}
\hline Paraíba & $\begin{array}{l}\text { Verificou-se a } \\
\text { elaboração de } \\
\text { uma minuta } \\
\text { e, na última } \\
\text { reunião, ficou } \\
\text { acordada uma } \\
\text { revisão final para } \\
\text { as atualizaçôes e } \\
\text { o fechamento do } \\
\text { Plano. }\end{array}$ & $\begin{array}{l}\text { Temáticas e possibilidades } \\
\text { de oferta de cursos de } \\
\text { formação continuada e } \\
\text { cursos especiais. } \\
\text { Apreciaçáo de proposta de } \\
\text { cursos de especialização. } \\
\text { Informaçóes diversas sobre } \\
\text { os acontecimentos no } \\
\text { campo da educaçáo. } \\
\text { Informações diversas sobre } \\
\text { iniciativas da secretaria de } \\
\text { educação e das IESs. }\end{array}$ & $\begin{array}{l}\text { A rotatividade e a falta de } \\
\text { autonomia de alguns participantes } \\
\text { do fórum como a Undime, por } \\
\text { exemplo. } \\
\text { Sobre as propostas de formação } \\
\text { continuada que deveriam partir } \\
\text { das escolas e não das IESs. } \\
\text { Parte dos cursos não funciona: } \\
\text { tem inscriçóes validadas, mas os } \\
\text { professores não fazem as matrículas. } \\
\text { A formação continuada passa a } \\
\text { ser ofertada sem a participação } \\
\text { do fórum ou açóes de formação } \\
\text { de professores ocorrendo } \\
\text { paralelamente ao fórum. } \\
\text { Grande oferta de cursos de } \\
\text { formação inicial pela IES, mas as } \\
\text { inscriçóes sáo baixas. } \\
\text { Falta de comunicação entre } \\
\text { secretaria de educação e Fórum. } \\
\text { Os dados de demanda da } \\
\text { plataforma são irreais. }\end{array}$ \\
\hline $\begin{array}{l}\text { Santa } \\
\text { Catarina }\end{array}$ & $\begin{array}{l}\text { O plano foi } \\
\text { apresentado } \\
\text { aos membros } \\
\text { do fórum na } \\
\text { primeira reunião } \\
\text { e se discutiu o seu } \\
\text { lançamento. } \\
\text { Verificando-se, } \\
\text { posteriormente, } \\
\text { a constituição de } \\
\text { uma comissão } \\
\text { para revisão do } \\
\text { planejamento. }\end{array}$ & $\begin{array}{l}\text { Discussōes sobre o papel } \\
\text { do fórum, Parfor e } \\
\text { responsabilidades da Sec. de } \\
\text { Educ., das IESs e da Capes. } \\
\text { Oferta dos cursos e vagas } \\
\text { para formaçáo inicial Parfor, } \\
\text { distribuição de turmas entre } \\
\text { as IESs. } \\
\text { Solicitaçóes de municípios } \\
\text { para implantação de polos } \\
\text { de apoio presencial da UAB. } \\
\text { Realização de seminário, } \\
\text { participaçáo de eventos e } \\
\text { promoção de debates sobre } \\
\text { formação docente. } \\
\text { Informes diversos da } \\
\text { Secretaria de Educação, } \\
\text { MEC/CAPES e das IESs. }\end{array}$ & $\begin{array}{l}\text { Qualidade da educação a } \\
\text { distância e sua oferta preferencial } \\
\text { para o curso de pedagogia. } \\
\text { Alto número de desistência nos } \\
\text { cursos do Parfor. } \\
\text { Demandas de formação } \\
\text { continuada sendo tratadas entre } \\
\text { MEC e IES sem passar pelo } \\
\text { fórum. } \\
\text { As condiçôes de trabalho/ } \\
\text { tempo do professor-aluno para } \\
\text { frequentar o curso do Parfor. } \\
\text { As dificuldades apresentadas pelo } \\
\text { professor-aluno relacionadas à } \\
\text { aprendizagem. }\end{array}$ \\
\hline
\end{tabular}

Parfor: Plano Nacional de Formaçâo de Professores; UFT: Universidade Federal do Tocantins; UAB: Universidade Aberta do Brasil; Uaitec: Universidade Aberta Integrada; IES: instituiçâo de ensino superior; MEC: Ministério da Educação; CAPES: Coordenação de Aperfeiçoamento de Pessoal de Nivel Superior; Undime: União dos Dirigentes Municipais de Educação; CNE: Conselho Nacional de Educação; UFG: Universidade Federal de Goiás.

Fonte: Brasil (2010). 
Sumariamente, compreende-se que tais realidades nos remetem a três compreensões ou concepçóes que se mostraram dominantes nas experiências analisadas e que determinaram o funcionamento e as realizaçóes desses colegiados. No primeiro caso, constata-se uma organização mais protocolar e de pouca ou nenhuma aposta nas possibilidades do fórum; no segundo, uma realidade que reflete a ação protagonista ou indutora de uma instituição participante - mais comumente a própria Secretaria de Educação do Estado; e, no terceiro, um engajamento coletivo que fez do fórum um espaço maior de debate e que, mesmo com limitaçóes e possíveis ressalvas, apresentou maior aposta coletiva em suas possibilidades.

Sobre os principais assuntos tratados nas reunióes, embora possamos observar uma variedade significativa de temas de um fórum para outro, alguns assuntos parecem ter sido recorrentes. É o caso das demandas da Plataforma Freire e a oferta de cursos e vagas — turmas do Parfor nas IESs, assim como da criação de polos de apoio presencial do sistema Universidade Aberta do Brasil (UAB) que, com exceção do fórum do Estado do Tocantins, foi um assunto presente nos demais, principalmente por meio das demandas apresentadas por municípios. É possível afirmar, portanto, que o atendimento das demandas por formação inicial de "primeira" ou "segunda licenciatura", na modalidade presencial ou a distância, foi, sem dúvida, o tema mais recorrente das reuniōes dos fóruns analisados.

Em menor grau, observamos que outros assuntos também fizeram parte das reunióes de mais de um dos fóruns analisados. Como o caso dos cursos de pós-graduação lato sensu e das especificidades das propostas curriculares desses cursos. Verificamos também alguns assuntos que, embora relevantes, apareceram nas reunióes de apenas um ou dois dos fóruns analisados. Foi o caso dos seguintes temas: as possibilidades de oferta de cursos de formação continuada e de cursos especiais - ponto de pauta no fórum da Paraíba; a formação de professores por meio de programas locais como no caso da criação de polos da Universidade Aberta Integrada (Uaitec) em Minas Gerias; e a realização de seminário, a participação em eventos e a promoção de debates sobre formação docente que consta terem ocorrido em Santa Catarina.

Observa-se ainda que, nos fóruns de maior longevidade, principalmente o da Paraíba e o de Santa Catarina, os pontos de pauta - com demandas de análise e de deliberações - cedem lugar, nas últimas reunióes, para um volume cada vez maior de informações gerais da Secretaria de Educação e de outras instituiçôes participantes. Também se observa a recorrência de reunióes em que os temas e as discussóes são livres, versando sobre diversas questóes que envolvem a educação no país, como PNE, editais, resoluçóes e solicitaçóes diversas demandadas pela CAPES ou pelo MEC.

Ainda que aparentemente os debates não tenham sido uma constante nas reunióes dos fóruns ou que tais debates não tenham sido registrados em atas, percebe-se que várias questóes foram suscitadas em discussóes desenvolvidas pelos 
participantes. Entre os diversos problemas debatidos em reunióes, três parecem particularmente importantes para a maioria dos fóruns: primeiro, a questão sobre o desenvolvimento da formação docente via UAB. Nesse caso, discutiu-se sobre quais instituições que poderiam ou deveriam ofertar cursos pelo sistema UAB; a divergência de avaliação feita pelo MEC e pelas universidades em relação aos polos de apoio presencial; a falta de condições para funcionamento dos polos; a resistência das universidades em ofertar cursos a distância; a qualidade da educação a distância; a necessidade de oferta presencial para alguns cursos, como o de Pedagogia, e sobre a orientação do Conselho Nacional de Educação (CNE) em dar preferência para cursos presenciais e, finalmente, sobre as possibilidades criadas pelo próprio governo federal, muito mais favoráveis, à oferta de cursos a distância.

A segunda questáo - que mereceu bastante destaque nos debates travados durante as reunióes - diz respeito à desproporcionalidade entre o número de vagas ofertadas nos cursos especiais (emergenciais) de licenciaturas, que seguia as demandas apresentadas pelas redes estaduais e municipais, e as matrículas efetivadas. Destacaram-se, nesse caso, o desinteresse dos professores pelas vagas oferecidas (principalmente, pela chamada "segunda licenciatura"); a existência de muitas vagas abertas e não preenchidas; a existência de cursos que não funcionaram (com inscriçóes válidas, mas que os professores não efetivaram as matrículas); e o alto número de desistência nos cursos do Parfor.

O terceiro problema refere-se a um possível esvaziamento do trabalho do fórum pelo desenvolvimento de um conjunto de ações referentes à formação docente, de maneira direta entre MEC/CAPES e Secretarias de Educação ou IESs. Sobre essa questão, as manifestações no interior dos fóruns referem-se, principalmente, às açôes de formação de professores ocorrendo paralelamente ao fórum e, sobretudo, à ausência da formação continuada no plano estratégico ou de ações de formação continuada que passaram a ser realizadas sem a participação do fórum, sendo tratadas de modo direto entre o MEC e as IES.

\section{Questões que contribuíram para a desconstrução dos fóruns}

As principias tarefas dos fóruns seriam: a elaboração, o acompanhamento e a avaliação do plano estratégico; a definição de prioridades e metas para formação docente em cada estado; a coordenação das ações de formação de professores e proposição de ações específicas para garantia de permanência e rendimento satisfatório dos professores de educação básica. Com tais atribuiçóes, esses colegiados teriam a incumbência de definir as diretrizes e as açóes necessárias à implementação da política de formação docente no âmbito estadual.

A ideia de reunir atores distintos, como os órgãos gestores da educação básica nos Estados, o governo federal e as universidades — para desenvolver uma 
política de formação docente, além de buscar dar cumprimento à perspectiva de uma política articulada - criava um importante espaço de proposição e de avaliação dos processos de formaçáo docente. No entanto, diversas questóes de ordem interna e externa, de maneira direta ou indireta, podem ter contribuído para a desarticulação dos fóruns.

A participação do Ministério da Educação, por representação direta ou por meio de um representante da CAPES, seria uma estratégia importante de articulação e valorização dos fóruns. Essa presença estreitaria as relações, deixaria o grupo mais informado e permitiria respostas mais ágeis às questôes levantadas. No entanto, pelo menos em relação aos estados analisados, a representação do MEC apenas se fez mais ativa nas primeiras reunióes, sendo totalmente ausente em alguns casos, como destacamos.

A questão da presidência dos fóruns também levantou questionamentos, pois o(a) secretário(a) de Estado da Educação nem sempre respeitava ou desenvolvia o devido processo de reflexão antes de tomar decisões ou realizar açóes atinentes às atribuiçôes do fórum. Sobre esse fato, percebe-se ainda que, em vários casos estudados, sendo o(a) secretário(a) necessariamente o(a) presidente, este(a) náo participava das reunióes ou passava por lá apenas esporadicamente. Quem assumia os trabalhos, quase sempre, era o seu suplente ou alguém indicado por ele(a) para se responsabilizar por essa tarefa. Há relatos também de que, em determinados casos, antes de enviar as questôes referentes à formação docente para o fórum, os dirigentes da Secretaria de Educação realizavam reuniôes paralelas, com IESs ou outras instituiçóes, deixando o fórum apenas como um local em que as decisóes eram comunicadas.

Outra questão que implicou diretamente no funcionamento dos fóruns diz respeito ao conjunto de demandas, muitas vezes, emanadas do próprio $\mathrm{Mi}$ nistério, o que sufocava seu funcionamento e atropelava suas funçóes específicas. Um dos principais prejuízos nesses casos foi a diminuição do espaço de debate para construção e avaliação da política de formação. Esse tipo de situação pôde ser notado, principalmente em relação aos processos de criação ou autorização para funcionamento de cursos ou espaços de formação, quase sempre sem um conhecimento mais profundo e uma discussão mais ampla, tendo em vista o cumprimento de prazos previamente determinados pelo MEC ou pela CAPES. Nesses casos, como observa Freitas (2012, p. 213):

Longe de se dedicarem a construir uma política de formação aos profissionais de estados e municípios em seus territórios, a partir de princípios nacionais gerais definidos pela Política Nacional de Formação, veem-se na contingência de administrar prazos e metas demandadas pelo MEC, à luz de uma concepção de sistema de gestáo gerencial restrita à utilização de instrumentos de gestão de processos e desgarrada dos movimentos do chão da escola. 
Em relação ao tema da "formação continuada", cuja necessidade e definição de ações deveriam constar do plano estratégico, conforme o inciso II, do art. $5^{\circ}$ do Decreto no 6.755/2009, não se observam contribuiçóes efetivas por parte dos fóruns sobre esse tópico. No caso dos fóruns analisados, essa questão não ganhou relevância significativa em nenhum deles. Percebe-se, por meio da leitura das atas de reunióes, que, em alguns fóruns, a "formação continuada" nem sequer fez parte dos assuntos tratados e, em outros, embora entrasse na pauta, algumas vezes, acabou por não se tornar uma ação significativa. Essa constatação nos remete tanto às dificuldades dos fóruns em relação ao plano estratégico, como já destacamos, quanto à condução dessa questão pelas diversas instâncias de governo envolvidas, que passaram a ignorar a existência dos fóruns. Um fragmento da ata de reuniáo do fórum da Paraíba, de 16 de dezembro de 2010, é bastante elucidativo sobre o que aconteceu em relação à "formação continuada", que foi tratada de maneira direta entre a universidade e o MEC.

A Professora Vânia explicou como ocorrem os trâmites para a oferta dos cursos de formaçáo continuada. Segundo ela, acontece uma chamada pública, um grupo de professores elabora o projeto, encaminha para apreciação do Reitor e depois para aprovação do MEC. Fazendo o uso da palavra, a Professora Vera enfatizou que tem sempre colocado nas reunióes, inclusive na qual o Professor Marcelo se fez presente, a questáo do papel do Fórum neste processo, pois o MEC está permitindo que ocorram essas chamadas públicas, pelas quais os cursos são aprovados e oferecidos sem a homologação do Fórum, sem que Estado e municípios definam estes cursos como necessidades (BRASIL, 2010).

A instituição do Comitê Gestor da Política Nacional de Formação Inicial e Continuada de Profissionais da Educação Básica, pela Portaria no 1.087, de 10 de agosto de 2011, embora, de um lado, tivesse, entre suas atribuiçóes, o objetivo de aprovar os planos estratégicos elaborados pelos Fóruns Estaduais Permanentes de Apoio à Formação Docente, indicar representante e disponibilizar informaçóes para esse mesmo fórum, de outro lado, abriu caminho para que o fluxo de açóes se desenvolvesse sem a participação desse fórum, principalmente quando estabeleceu como função do comitê: "III — analisar a demanda e organizar a oferta dos cursos nos estados onde o Fórum Estadual Permanente de Apoio à Formação Docente não elaborar o plano estratégico" (art. 3º) (BRASIL, 2011). Em ato contínuo, a criação do referido comitê gestor no interior das IESs, com a incumbência de coordenar o monitoramento de dados e o seu fornecimento ao MEC, contribuiu ainda para reforçar a constituição de relaçóes diretas sem que fosse necessária nenhuma ação do fórum.

Por fim, e não menos importante, também devemos destacar o esgotamento das atividades do Parfor. Esse programa, que ocupou parte significativa da 
agenda dos fóruns em cada Estado, teve uma rápida redução das suas atividades ainda nos primeiros anos de sua implementação. Conforme o Relatório de Gestão DEB 2009-2014 (BRASIL, 2015a), do total de 24.601 matrículas para esse programa, em 2010, em turmas de licenciatura, segunda licenciatura e formação pedagógica, reduziu-se para 8.342, em 2014. Sendo um programa emergencial, que visava a ministrar cursos superiores e formação continuada para docentes em serviço, em grande parte, limitou-se a tratar da oferta de licenciaturas para um público específico que aspirava à certificação em nível superior. Com o esgotamento, ainda que parcial, da demanda apresentada pelos professores que não tinham curso superior ou que buscavam formação em outra licenciatura, tornou-se desnecessária grande parte da estrutura mobilizada em torno do referido programa. Nesse caso, aqueles fóruns que se constituíram e que estruturaram toda a sua programação em função das questóes referentes ao Parfor foram perdendo o significado em proporçóes equivalentes ao plano, tendo sofrido uma espécie de "perda de finalidade" na mesma proporção do esgotamento das açóes emergenciais priorizadas.

Assim, tendo em vista todas essas questóes que impactaram o funcionamento dos fóruns, percebe-se grande incoerência no que refere ao seu caráter permanente, como consta em seu próprio nome - Fóruns Estaduais Permanentes de Apoio à Formação Docente. Entende-se que a “permanência” pode ser compreendida tanto no sentido de que ele não teria interrupçóes quanto no sentido de que não seria dissolvido, pelo menos, em curto prazo. No entanto, sob qualquer compreensão, os fóruns não se constituíram como permanentes: alguns não tiveram uma existência efetiva, como já relatamos, outros oscilaram em função das mudanças políticas nos Estados, e outros nunca conseguiram regularidade em seu funcionamento. Além disso, pelo que se pode constatar por meio dos registros, apenas um fórum realizou reunião em 2016, e poucos conseguiram estender suas atividades até 2015 . Portanto, não houve nenhum encerramento das atividades dos fóruns; eles simplesmente se sucumbiram.

É importante ressaltar a mudança na conjuntura política brasileira após o golpe político, parlamentar, jurídico, midiático e sexista, em 2016, que retirou do poder a presidente legitimamente eleita pelo voto popular. Essa mudança parece ter representado uma verdadeira "pá de cal" nas iniciativas governamentais "pré-golpe" de criação e de organização de uma Política Nacional de Formação Docente. Evidencia-se, mais uma vez, na realidade educacional brasileira, a adoção de uma política de governo - e não uma política sustentável de Estado que não tenha descontinuidade com a alteração no cenário político no país.

Finalmente, constata-se, por meio da análise neste texto apresentada, o enorme desafio e a grande complexidade do chamado "regime de colaboração". No caso da criação e do desenvolvimento dos fóruns, neste estudo analisados, esse regime aproximou-se mais de um processo de articulação, em que o governo federal assume o papel de articulador das açóes junto aos Estados e municípios, 
distanciando-se, portanto, de um "sistema nacional em sentido próprio", como defendido por Saviani (2010, p. 385). Percebe-se que o processo de colaboraçáo observado tem se mostrado frágil no sentido de construir uma ação unificada, envolvendo adequadamente todos os entes federados. Permanece, portanto, uma lacuna quanto à divisão de responsabilidades para cada ente da federação, possibilitando interpretações diversas na condução das ações e, principalmente, a inconstância das açóes promovidas pelo governo federal, sobretudo no que se refere à formação docente.

\section{Considerações finais}

A formação docente, como política nacional, precisa, em nossa compreensão, ser debatida e assimilada em todas as suas dimensóes. As consideraçóes sobre sua relevância estratégica para o conjunto dos problemas da educação, deslocadas de uma ação efetiva, com nítida responsabilidade institucional, têm se tornado, na maioria das vezes, uma retórica vazia. Os experimentos pontuais e focalizados, embora com reconhecidos méritos em alguns casos, estarão fadados ao esquecimento diante de qualquer mudança do humor político ou econômico que venha ocorrer.

Assim, a perspectiva de uma política nacional, organicamente articulada, deverá trazer para a discussão não apenas as questōes referentes aos padróes de qualidade que se quer, mas também as possibilidades e estratégias para sua promoção, algo que nos parece bastante complexo, principalmente se o objetivo do governo federal se resume, simplesmente, a induzir a ação dos Estados e municípios, por meio de um "regime de colaboração".

A análise que apresentamos sobre os Fóruns Estaduais Permanentes de Apoio à Formação Docente revelou que a ação pública estatal, no que se refere à formaçáo de professores, reproduz a tradição brasileira sem enfrentar os grandes problemas existentes. A intensa abertura do ensino superior para a iniciativa privada, a flexibilização curricular e o pouco interesse das instituiçóes públicas na formação docente continuam favorecendo uma realidade em que a diplomação em massa e a criaçáo de uma grande área de investimento para a iniciativa privada se tornaram objetivos principais. No entanto, as consequências negativas dessa realidade não têm servido para uma crítica ao modelo, mas sim para justificar a contínua necessidade da "formação em serviço", por meio de programas emergenciais e provisórios, deslocando a formação da universidade para a escola e minimizando a necessidade de uma sólida formação teórica para o exercício da docência.

Defende-se, portanto, que a formação docente seja debatida e compreendida como política pública, considerando, sobretudo, sua relação com as determinaçóes de uma sociedade marcada pela desigualdade, pelo preconceito e pela exclusão (OLIVEIRA, 2007). É necessário, pois, o seu reconhecimento como 
responsabilidade coletiva e como área educacional prioritária para a ação pública estatal, reforçando o papel da universidade, da integraçáo teoria e prática e da valorização do trabalho docente.

\section{Notas}

1. Verifica-se que o regime de colaboração, que deve orientar a realização das competências comuns da União, dos Estados, do Distrito Federal e dos Municípios, previsto na Constituição de 1988, embora de uso corrente nos documentos oficiais, não conta com uma compreensão explícita, no sentido de contribuir para ampliar a cooperação e articulação dos entes federados na implementação das políticas sociais. Compreende-se que, para além do estabelecimento de normas para o processo de cooperação, como previsto no Parágrafo Primeiro do art. $23 \mathrm{da} \mathrm{CF} / 88$, no que se refere às políticas educacionais, o regime de colaboraçáo deve ser capaz de favorecer a participaçáo dos diversos sujeitos envolvidos, enfrentar as desigualdades regionais, integrar as açóes evitando a competição e a desarticulaçâa e, sobretudo, evitar a omissão do governo federal para a realização dos investimentos necessários.

2. Compreendido como "o profissional que exerce o magistério sem possuir a habilitação mínima exigida” (AUGUSTO, 2010, p. 1).

3. Conforme o art. 62 da Lei de Diretrizes e Bases da Educação Nacional (LDB no 9.394/96), "A formação de docentes para atuar na educação básica far-se-á em nível superior, em curso de licenciatura, de graduação plena, em universidades e institutos superiores de educaçáo, admitida, como formação mínima para o exercício do magistério na educação infantil e nas quatro primeiras séries do ensino fundamental, a oferecida em nível médio, na modalidade Normal” (BRASIL, 1996).

4. A definiçấo de capacitação colocada na referida nota, trata-se de uma construção dos autores com base no termo CAPACITAR, que significa "tornar capaz" (FERREIRA, 2004, p. 207).

\section{Referências}

AUGUSTO, M. H. Professor leigo. In: OLIVEIRA, D. A.; DUARTE, A. M. C.; VIEIRA, L. M. F. Dicionário: trabalho, profissão e condição docente. Belo Horizonte: UFMG/ Faculdade de Educação, 2010. 1 CD-ROM.

BRASIL. Constituição (1988). Constituição da República Federativa do Brasil. Brasília, DF: Senado Federal: Centro Gráfico, 1988. 292 p.

BRASIL. Lei no 11.738, de 16 de julho de 2008. Regulamenta a alínea "e" do inciso III do caput do art. 60 do Ato das Disposiçóes Constitucionais Transitórias, para instituir o piso salarial profissional nacional para os profissionais do magistério público da educação básica. Diário Oficial da Uniáo, Brasília, 17 jul. 2008.

BRASIL. Coordenação de Aperfeiçoamento de Pessoal de Nível Superior (CAPES).

Fóruns Estaduais. Brasil: CAPES, 2010. Disponível em: < http://www.capes.gov.br/ educacao-basica/parfor/foruns-estaduais/3387-foruns-estaduais >. Acesso em: 5 set. 2016. 
BRASIL. Ministério da Educaçáo. Portaria no 1.087, de 10 de agosto de 2011. Institui o Comitê Gestor da Política Nacional de Formação Inicial e Continuada de Profissionais da Educação Básica e define suas diretrizes gerais. Diário Oficial da União. Brasília, 11 ago. 2011.

BRASIL. Coordenação de Aperfeiçoamento de Pessoal de Nível Superior (CAPES). Relatório de Gestáo DEB 2009-2014. Brasília: CAPES, 2015a. v. 1. Disponível em: $<$ https:/www.capes.gov.br/images/stories/download/bolsas/20150818_DEB-relatoriode-gestao-vol-1-com-anexos.pdf >. Acesso em: 31 out. 2016.

BRASIL. Decreto n 6.755, de 29 de janeiro de 2009. Institui a Política Nacional de Formação de Profissionais do Magistério da Educação Básica, disciplina a atuação da Coordenação de Aperfeiçoamento de Pessoal de Nível Superior - Capes no fomento a programas de formaçáo inicial e continuada, e dá outras providências. Diário Oficial da Uniáo, Brasília, 30 jan. 2009a.

BRASIL. Lei no 9.394/96. Lei de Diretrizes e Bases da Educação Nacional. Diário Oficial da Uniáo, Brasília, 23 dez. 1996.

BRASIL. Lei $\mathrm{n}^{\circ}$ 11.502, de 11 de julho de 2007. Modifica as competências e a estrutura organizacional da fundaçáo Coordenaçáo de Aperfeiçoamento de Pessoal de Nível Superior Capes, de que trata a Lei n o 8.405, de 9 de janeiro de 1992 e altera as Leis no 8.405, de 9 de janeiro de 1992, e 11.273, de 6 de fevereiro de 2006, que autoriza a concessáo de bolsas de estudo e de pesquisa a participantes de programas de formação inicial e continuada de professores para a educação básica. Diário Oficial da Uniáo, Brasília, 12 jul. 2007.

BRASIL. Ministério da Educação. Portaria no 883, de 16 de setembro de 2009. Estabelece as diretrizes nacionais para o funcionamento dos Fóruns Estaduais Permanentes de Apoio à Formaçáo Docente, criados pelo Decreto 6.755, de 29 de janeiro de 2009. Diário Oficial da Uniáo, Brasília, 17 set. 2009 b.

BRASIL. Plano Nacional de Educação (PNE). Lei no 13.005, de 25 de junho de 2014. Aprova o Plano Nacional de Educação PNE e dá outras providências. Diário Oficial da União, Brasília, 26 jun. 2014.

BRASIL. Resolução CNE/CP no 2, de $1^{\text {o }}$ de julho de 2015. Define as Diretrizes Curriculares Nacionais para a formaçáo inicial em nível superior (cursos de licenciatura, cursos de formaçáo pedagógica para graduados e cursos de segunda licenciatura) e para a formação continuada. Diário Oficial da Uniáo, Brasília, Seção 1, p. 8-12, 2 jul. 2015 b.

FERREIRA, A. B. H. Miniaurélio: o minidicionário da língua portuguesa. 6. ed. rev. atualiz. Curitiba: Posigraf, 2004. 896p.

FREITAS, H. C. L. de. Federalismo e formação profissional: Por um sistema unitário e plural. Revista Retratos da Escola, Brasília, v. 6, n. 10, p. 211-225, jan./jun. 2012. http://dx.doi.org/10.22420/rde.v6i10.180

GATTI, B. A. Formação inicial de professores para a educação básica: pesquisas e políticas educacionais. Estudos de Avaliaçáo Educacional, São Paulo, v. 25, n. 57, p. 24-54, jan./ abr. 2014. http://dx.doi.org/10.18222/eae255720142823

MAUÉS, O. C. Reformas Internacionais da Educação e Formação de Professores. Cadernos de Pesquisa, n. 118, p. 89-118, mar. 2003. http://dx.doi.org/10.1590/S0100$\underline{15742003000100005}$ 
OLIVEIRA, D. A. Política Educacional e a Re-Estruturação do Trabalho Docente: reflexóes sobre o contexto Latino-Americano. Educaçáo \& Sociedade, Campinas, v. 28, n. 99, p. 355-375, maio/ago. 2007. http://dx.doi.org/10.1590/S0101-73302007000200004

TANURI, L. M. História da formação de professores. Revista Brasileira de Educaçáo, n. 14, p. 61-88, maio-ago. 2000.

TORRES, R. M. Balance y perspectiva de la formación docente en América Latina. Ciencia y Sociedad, v. 25, n. 3, p. 368-394, jul.-set. 2000. https://doi.org/10.22206/ cys.2000.v25i3.pp368-94

SAVIANI, D. Sistema Nacional de Educação articulado ao Plano Nacional de Educação.

Revista Brasileira de Educaçáo, v. 15, n. 44, maio/ago. 2010.

ZEICHNER, K. M. Políticas de formaçáo de professores nos Estados Unidos: por que e como elas afetam vários países no mundo? Belo Horizonte: Autêntica, 2013.

\section{SOBRE OS AUTORES}

Cleomar Locatelli é pós-doutor em Educação pela Universidade Federal de Minas Gerais (UFMG). Professor da Universidade Federal do Tocantins (UFT).

Júlio Emílio Diniz-Pereira é doutor em Educação pela Universidade do Estado de Wisconsin, em Madison, nos Estados Unidos. Professor do Programa de Pós-graduação da Faculdade de Educação da Universidade Federal de Minas Gerais (FaE/UFMG).

Recebido em 14 de outubro de 2017.

Aceito em 20 de setembro de 2018. 